\title{
Delivery patterns among women at the Tamale West Hospital from 2012 to 2015, Northern Region, Ghana
}

\author{
F. A. Ziba ${ }^{1}$, P.P.M. Dapare ${ }^{2}$, P. Kafari ${ }^{1}$, K. Tigawuti $^{1}$ and S. B. Nte-Ajal ${ }^{1}$ \\ ${ }^{1}$ Department of Nursing, ${ }^{2}$ Department of Biomedical Laboratory Science School of Allied Health Sciences, University for Development \\ Studies, Tamale, Ghana
}

\begin{abstract}
The study traces the likely route of the movement of fertility through the demographic transition from the available data obtained from the Tamale West Hospital. The information is critical for construction of population projections as well as for monitoring and evaluating action programs. This research was conducted to assess delivery patterns among women in the Tamale West Hospital for the four years under study. Retrospective cohort study design was used for this study. The data for the research work was from the Public Health Unit of Tamale West Hospital. Findings from the research revealed that for the period of the four years (2012-2015), a total of 11,083 babies were delivered with the majority (54.3\%) being male babies. Further results showed that the highest (31.6\%) deliveries of babies by women were in 2012. The study also found that of the $30(0.27 \%)$ of babies with newborn complications, majority $28(93 \%)$ suffered opthalmia neonatorum and $2(7 \%)$ suffered from asphyxia $(7 \%)$. A total of $14(0.13 \%)$ maternal deaths were recorded of which 2015 recorded the highest (64.3\%) number of maternal deaths. The causes of the deaths included sepsis, obstructed labour, eclampsia, unsafe abortion and hemorrhage. The study highlights the high numbers of births been recorded in the region. These huge numbers have a corresponding impact on the country's population, with its associated problems. Health facility delivery is persistently high in the Tamale Metropolis and the birth seasonality peaked in May, September and October. The study therefore recommends continuous health education in the metropolis to minimize issues related to labour complications and maternal and infant mortality.
\end{abstract}

Journal of Medical and Biomedical Sciences (2017) 6(2), 38- 43

Keywords: childbirth, maternal health, Pregnancy, Tamale

\section{INTRODUCTION}

Childbirth is a risk producing event (Andaleeb, 2001;

Astolfi and Zonta, 2002). Timely and adequate medical care for women who experience obstetric complications is an option for mitigating the risk (Agha and Do, 2009). Childbirth takes place in different forms throughout the world depending on the cultural contexts of each community (Miller, 2005; Agha and Do, 2009). In some areas, mothers go through the process of attended child birth. A few seek attendance from midwives and obstetricians, but two thirds of births in the world are assisted also by traditional birth attendants who are not trained (Seoud et al., 2002; Miller, 2005).

Correspondence: Florence A. Ziba, Department of Nursing, School of Allied Health Sciences, University for Development Studies, Tamale

E-mail:aziba@uds.edu.gh
Globally, interpretation of trends in pattern of birth rates using conventional age-period-cohort analyses is made difficult by the lack of a unique set of parameters specifying any given model (Andaleeb, 2001; Astolfi and Zonta, 2002). Because of difficulties inherent in age-period-cohort models, neither the magnitude nor the direction of a linear trend in birth cohort effects can be determined unambiguously in a single year.

This leads to considerable uncertainty in making inferences regarding delivery pattern based on birth cohort or calendar period trends in just using one year (Joseph et al., 2005). In Ghana, the changing patterns of women becoming pregnant at an advanced age have a serious public health impact because of increased risks of adverse outcomes (Ghana Health Service, 2007). Women are encouraged to deliver their babies in health facilities as a 
Pattern of childbirth in Tamale from 2012-2015

Ziba et al.,

strategy to implement maternal health outcome (World Health Organization, 2012).

In sub-Saharan African, most pregnant women lack access to maternal health care including antenatal care that would save their lives during pregnancy and mitigate disability during child birth, tens of thousands of women, who have access to the care turn up late, make fewer medical contacts and a bigger number of expectant women do not seek the service for various reasons (Karatas et al., 2005).

In the northern region, most pregnant women do not book for ANC services while others may book late (Hill et al., 2010). Some may change health facility without disclosing their obstetric history to the new health care giver. Others may go to prayer houses to deliver their babies because of the general ignorance in many churches involving their ministers and the memberships. These pregnant mothers end up with morbidities and mortalities. In the Tamale West Hospital, no study has outlined the delivery pattern among pregnant women using retrospective cohort study. Therefore, this study was conducted to address this important gap in the literature.

\section{MATERIALS AND METHODS}

Study design and population

A retrospective cohort study design was used. The study population included all records of pregnant women who delivered from January, 2012 to December, 2015 at the Tamale West Hospital.

\section{Study site}

The research was carried out at the Tamale West Hospital. The Tamale West hospital serves as a referral Centre for clinics and nearby districts like, Tolon/Kumbungu central Gonja and Savelegu/Nanton all in the Northern Region of Ghana. It provides 24 hours' service and renders services including Medical services, ANC services, PMTC and VCT Services, Laboratory and X-ray Services, Ultra Sound Service, Eye Clinic, Gynecological Services, NHIS Service and surgical services.

\section{Data collection}

Secondary data was collected from the public health unit of the hospital which kept data from the labour ward of the hospital. The obstetric information on the form included: mode of delivery (normal vaginal, delivery using operative procedure such as vacuum or forceps and caesarean section), outcome of delivery (single, twins, triplets and others), parity ( 0 , $1-2,3-4,>5)$, birth abnormalities, age group of mother at delivery and complications of delivery (e.g. vesico-vaginal fistula).

\section{Statistical analysis}

The data was entered into Microsoft Excel 2010 spread sheet for window version and imported to Statistical Package for Social Sciences version 22.0 (SPSS) to for analysis. Data was presented in table and charts.

\section{RESULTS}

\section{Distribution of ages of mothers}

Figure 1 shows the age ranges in years of the women whose records were used for the analysis. From the Figure, 5,964 (34\%) of the women were aged between $20-24$ years, $3,713(21 \%)$ of the women were aged between 30-34 years, 3,345 (19\%) were aged above 34 years, 2,412 (14\%) of the women were aged between 25-29 years and 2134 (12\%) of the women were aged between 15-19 years.

Table 1 represents the gestational periods at antenatal care registration. Most of the women, 9,419 representing 53.6\% initiated ANC services during the

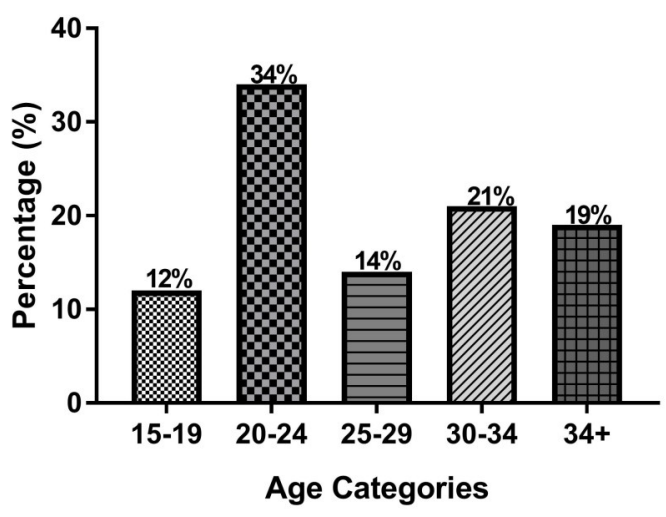

Figure 1: proportions of the age categories of the women 
Pattern of childbirth in Tamale from 2012-2015

Ziba et al.,

first trimester of their pregnancy whilst $8149(46.4 \%)$ of the women initiated ANC services during the second trimester of their pregnancy. No one therefore initiated $\mathrm{ANC}$ visit during the third trimester.

Table 1: Gestational Period at registration

\begin{tabular}{ll}
\hline Variables & Number (\%) \\
\hline First trimester & $9419(53.6 \%)$ \\
Second Trimester & $8149(46.4 \%)$ \\
\hline
\end{tabular}

Data presented as number and percentages

Trends of deliveries during the years under review

Table 2 shows the total deliveries that were conducted from 2012-2015 at the TWH. From the results, 3,511 women representing $(31.6 \%)$ delivered in 2012. 3,410 (30.8\%) delivered in 2014 whilst 2,101 $(19 \%)$ and 2,061 (18.6\%) deliveries were conducted in 2015 and 2013 respectively based on the data. The total number of babies delivered during the four years' review was eleven thousand and eighty-three babies. Majority of the deliveries 6021 (54.3\%) during the four years under review were males whilst $5062(45.7 \%)$ of the babies were females.
Table 2: Proportions of delivery numbers by years and gender of babies

\begin{tabular}{lc}
\hline Variables & Number (\%) \\
\hline Birth by years & \\
2012 & $3511(31.6 \%)$ \\
2013 & $2061(18.6 \%)$ \\
2014 & $3410(30.8 \%)$ \\
2015 & $2101(19.0 \%)$ \\
Total births & \\
Babies & $11083(100 \%)$ \\
Total births by sex & \\
Male & $6021(54.3 \%)$ \\
Female & $5062(45.7 \%)$ \\
\hline
\end{tabular}

Data presented as number and percentages

As shown in Figure 2, the results of stillbirths were compared graphically as depicted in the Figure with the peak for the fresh stillbirth being October and macerated stillbirth being November during the entire four years under review. There appeared to have been a slight trend in stillbirths among babies in the four years under review.

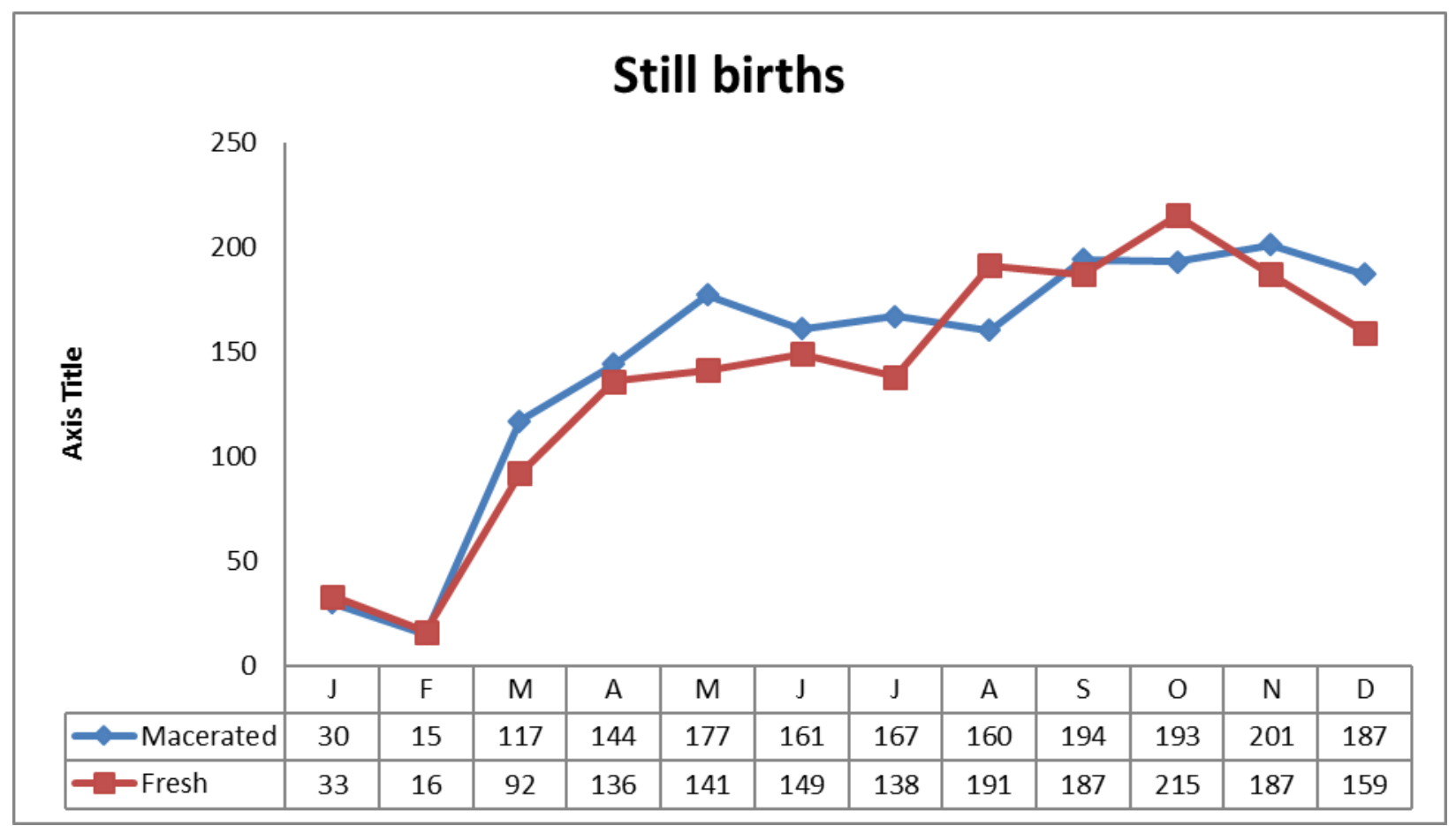

Figure 2: Stillbirth by months from 2012-2015 
Pattern of childbirth in Tamale from 2012-2015

Ziba et al.,

Proportions of newborn birth complications and abnormalities

Figure 3 shows the proportions of complications recorded in the years under review. About 30 $(0.27 \%)$ of the newborns suffered complications. Out of which majority, $28(93 \%)$ suffered from opthalmia neonatorum and $2(7 \%)$ suffered from asphyxia (figure 3).

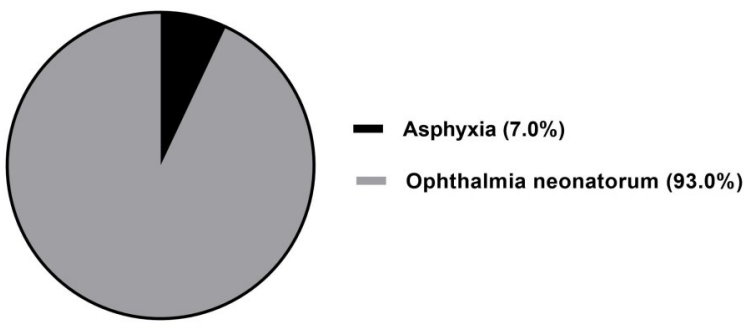

Figure 3: Proportions of Newborns complications

Figure 4 depicts the proportions of babies with birth abnormalities. In all, $15(0.14 \%)$ of the babies had birth abnormalities. Of this number, majority 7 (47\%) were Polydactyly, 2 (13\%) babies had hydrocephalus, $2(13 \%)$ had cleft palate and $4(27 \%)$ had abnormal organs (figure 4).



Figure 4: Proportions of Abnormalities in newborns

Maternal deaths in years under review

Table 3 shows the proportions of maternal death by years and by causes of death. A total of $14(0.13 \%)$ deaths were recorded during the four years under review. Of the total number of maternal deaths, 2015 recorded the highest number of maternal deaths, $9(64.3 \%)$ and the least being $1(7.1 \%)$ in 2013. Majority of the maternal deaths were due to sepsis $6(42.9 \%), 4(28.6 \%)$ obstructed labour, with the least being eclampsia and unsafe abortion representing $1(7.1 \%)$ respectively.

Table 3: Total maternal death by years

\begin{tabular}{ll}
\hline Variables & Number (\%) \\
\hline Death by years & $2(14.3 \%)$ \\
2012 & $1(7.1 \%)$ \\
2013 & $2(14.3 \%)$ \\
2014 & $9(64.3 \%)$ \\
2015 & \\
Causes of maternal death & $2(14.3 \%)$ \\
Hemorrhage & $6(42.9 \%)$ \\
Sepsis & $1(7.1 \%)$ \\
Unsafe abortion & $1(7.1 \%)$ \\
Eclampsia & $4(28.6 \%)$ \\
Obstructed labour & \\
\hline Data presented as number and percentages \\
DISCUSSION
\end{tabular}

There are considerable uncertainties in making inferences regarding delivery patterns based on birth cohort or calendar period trends in just using one year (Joseph et al., 2005). In Ghana, the changing patterns of women becoming pregnant at an advanced age have a serious public health impact because of increased risks of adverse outcomes (Ghana Health Service, 2007). In Tamale, no known study has outlined the delivery patterns among pregnant women using retrospective cohort study. This study therefore aimed at filling this important gap in the literature.

Results from the data obtained indicated that majority of the women delivered during 2012 calendar year. The study recorded a total birth of eleven thousand and eighty-three babies (11,083). From the results, the trend of male babies exceeding the number of female babies for the first two years was observed. In 2012 and 2013, the total percent of male babies exceeded the total number of females by $1.8 \%$. Evidently presenting the issue in this research, the study could not clearly show a pattern of either male or female babies being delivered by women within any calendar year. 
Pattern of childbirth in Tamale from 2012-2015

Ziba et al.,

From the results, all the women who delivered at the Tamale West Hospital sought antenatal clinic services adequately before they delivered. Whiles most of the women initiated antenatal clinic services during the first trimester, others initiated it during the second trimester. It is however imperative for women to be continuously encouraged to seek antenatal care on time to avert any possible birth complications.

From the study, the most common birth complication was opthalmia nonatorum representing 28 $(93 \%)$ whilst a relatively smaller number suffered from asphyxia $2(7 \%)$. The study also observed an increasing pattern of babies being born with birth abnormalities particularly polydactyly (extra fingers). This is a cause for concern and raises many questions about whether hospital authorities and Ghana Health Service have seen it as a need to raise awareness on the possible causes of extra fingers especially for antenatal clinics in health centers.

Findings from the research revealed that a total of 14 maternal deaths were recorded during the four years under review in the Tamale West Hospital. Although this figure might be small in terms of size compared to the total population of women whose records were used, it still calls for concern to completely eliminate maternal mortality from the country. This finding supports the survey done by the Ghana Health Service (2010) where it was revealed that maternal and neonatal death rates in Ghana have been steadily declining over the years as a result of a combination of factors including improvements in health conditions, increasing education and modernization. From the results, it was realized that the major cause of death among the women was sepsis, causing $42.6 \%$ of the deaths.

This finding from the research is at variance with the results presented by the Ghana Statistical Service (GSS) (2009) that the commonest cause of maternal mortality is hemorrhage, representing $24 \%$ of the cases in Ghana and has been identified as the leading cause of maternal deaths in Ghana (Ghana Statistical Service (GSS), 2009). It was also revealed that 4 $(28.6 \%)$ of the women die as a result of obstructed labour. This finding is in consonance with the findings made by the Ghana Health Service (2010) where it was reported that the frequent cause of maternal death was obstructed labour, which occurs when the fetus' head is too big compared with the mother's pelvis or if the baby is abnormally positioned.

\section{CONCLUSION}

The study highlights the huge numbers of deliveries recorded within the years under review. This huge number of babies could increase the country's population with its associated problems. It also brings to bare the declining numbers of maternal deaths. The research recommends continuous health education program that enables more women to utilize delivery care.

\section{COMPETING INTERESTS}

The authors declare that they have no competing interests.

\section{REFERENCES}

Agha S. and Do M. (2009) The quality of family planning services and client satisfaction in the public and private sectors in Kenya. International Journal for Quality in Health Care 21(2), 87-96.

Andaleeb S.S. (2001) Service quality perceptions and patient satisfaction: a study of hospitals in a developing country. Social science \& medicine 52(9), 1359-1370.

Astolfi P. and Zonta L.A. (2002) Delayed maternity and risk at delivery. Paediatr Perinat Epidemiol 16(1), 67-72.

Ghana Health Service (2007) 2006 Annual Report. Accra: GHS.

Ghana Health Service (2010) 2009 Annual Report. Accra: GHS.

Ghana Statistical Service (GSS) (2009) Ghana Demographic and Health Survey 2008. Accra, Ghana: GSS, GHS, and ICF Macro.

Hill Z., Tawiah-Agyemang C., Okeyere E., Manu A., Fenty J. and Kirkwood B. (2010) Improving hygiene in home deliveries in rural Ghana: how to build on current attitudes 
Pattern of childbirth in Tamale from 2012-2015

Ziba et al.,

and practices. The Pediatric infectious disease journal 29(11), 1004-1008.

Joseph K.S., Allen A.C., Dodds L., Turner L.A., Scott H. and Liston R. (2005) The perinatal effects of delayed childbearing. Obstetrics \& Gynecology 105(6), 1410-1418.

Karatas G., Dede S., Arcan A., Altinbas S. and Kandemir O. (2005) Pregnancy Outcome in Women Aged 40 Years and Older. J Turk German Gynecol Assoc 6(2), 114-117.

Miller D.A. (2005) Is advanced maternal age an independent risk factor for uteroplacental insuf- ficiency? American journal of obstetrics and gynecology 192(6), 1974-1980.

Seoud M.A.-F., Nassar A.H., Usta I.M., Melhem Z., Kazma A. and Khalil A.M. (2002) Impact of advanced maternal age on pregnancy outcome. American journal of perinatology 19 (01), 001-008.

World Health Organization (2012) Trends in maternal mortality: 1990 to 2010: WHO, UNICEF, UNFPA and The World Bank estimates. Trends in maternal mortality: 1990 to 2010: WHO, UNICEF, UNFPA and The World Bank estimates.
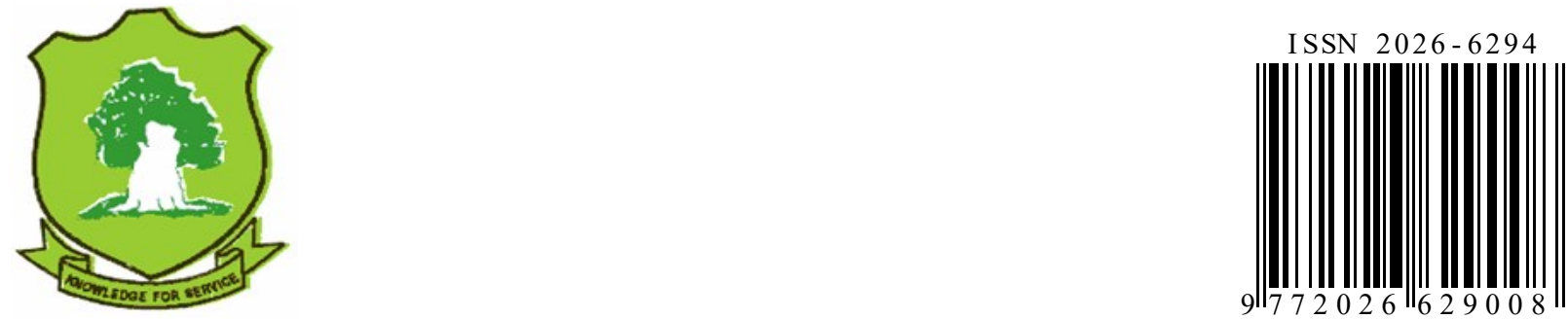